\title{
SOME BIOLOGICAL APPLICATIONS OF NEUTRONS AND ARTIFICIAL RADIOACTIVITY*
}

\author{
By Dr. John H. LAWRENCE, \\ Radiation laboratory, Univ́ersity of California, Berkeley
}

$\mathrm{T}$ HE biological and medical sciences are being stimulated and benefited by the recent discoveries of the nuclear physicist in a manner similar to that following the discovery of the naturally occurring radioactive elements and the production of X-rays. The nuclear physicist can now induce radioactivity in practically all of the elements, and he can harness a beam of neutrons of intense biological activity. This new wonderland for the biologist has been brought about by such events as the first successful experiments of Joliot and Curie in artificial radioactivity, the discovery of the neutron by Chadwick, the discovery of heavy hydrogen by Urey, and the development of the cyclotron by $\mathrm{E}$. O. Lawrence and his associates.

During the past four years, workers at the University of California have been intensely interested in the biological applications of these products of the physicist, and recently a new medicalbiological laboratory dedicated to this study and housing the new 220-ton cyclotron-the William $\mathrm{H}$. Crocker Radiation Laboratory-has been completed in Berkeley. Because of its ability to produce large quantities of the various radio-elements and neutron rays, the cyclotron is the nucleus of this unit. The Laboratory is, however, staffed not only by physicists, but also by chemists, biologists, cytologists, bacteriologists, physicians and radiologists - all of whom are interested in both the fundamental and practical problems concerned with the interaction of radiation and matter. My purpose here is to discuss briefly some of the investigations carried on in this laboratory or in conjunction with it. Unfortunately, there is not sufficient space to discuss the extensive and important work being done in this field in other laboratories.

When Hevesy first used radium $\mathrm{D}$, an isotope of lead, as a 'tracer' of lead movement in plants, the potential value of similar isotopes of elements which are important in physiological processes, such as phosphorus, sodium, iron and iodine, became apparent. These and other radioactive

* Based in part on a paper given before Section A (Mathematical and Physical Sciences) of the British Association, given on August 31 and September 1, 1939, at Dundee. isotopes are now available; and, since they are chemically like their inactive relatives, their radiations simply label or tag them and enable the investigator (with the aid of a Geiger counter) to study their average exchange and distribution in biological and chemical processes, in health and disease. The effect of irradiation on the reaction is avoided by the use of sufficiently small 'tracer' amounts. On the other hand, many of these isotopes may be used as potent sources of radiation if the metabolism of the element in question is not being studied. In Table 1 are listed some of the isotopes that are used in this University. A brief discussion of studies in which these isotopes are employed follows.

\begin{tabular}{|c|c|c|c|}
\hline $\begin{array}{l}\text { Atomic } \\
\text { number }\end{array}$ & Radio-clement & Radiation & Half-life \\
\hline 1 & Hydrogen (3) & Beta & $150-170$ days \\
\hline 6 & Carbon (11) & Positron and gamma & 20.5 minutes \\
\hline 11 & Sodium (24) & Bata and ganma & $14 \cdot 8$ hours \\
\hline 15 & Phosphorus(32) & Beta & $14 \cdot 3$ days \\
\hline 16 & Sulphur (35) & Beta & 88 days \\
\hline 17 & Chlorine (34) & Positron and gamma & 33 minutes \\
\hline 19 & Potassium (42) & Beta and gamma & $12 \cdot 4$ hours \\
\hline 20 & Calcium (45) & Beta and gamma & 180 days \\
\hline 26 & Iron (59) & Beta and gamma & 47 days \\
\hline 35 & Bromine (82) & Beta and gamma & 34 hours \\
\hline 53 & Iodine (126) & Beta and gamma & 13 days \\
\hline
\end{tabular}

Radioactive hydrogen is written ${ }_{1} \mathrm{H}^{8}$, in contrast to ordinary hydrogen $\left({ }_{2} \mathrm{H}^{1}\right)$ and heavy hydrogen $\left.{ }_{(} \mathrm{H}^{2}\right)$, and has only recently been discovered by Alvarez and Cornog of this Laboratory. This newly labelled form is used in biological work and promises to become a valuable adjunct to heavy hydrogen, which has been so extensively used in 'tracer' studies. Although radio-carbon has a very short half-life (20.5 minutes), Ruben, Hassid and Kamen are successfully using it in the study of photosynthesis. Leaves of barley plants grown in an atmosphere of $\mathrm{C}^{*} \mathrm{O}_{2}$ form radioactive carbohydrates ${ }^{\dagger}$, even when the plants are kept in darkness prior to exposure to $\mathrm{C}^{*} \mathrm{O}_{2}$. The bulk of the radioactive material found in the plant is watersoluble and does not contain carbohydrate, carbonate, keto acids or pigments. Jenny and Overstreet of the College of Agriculture grew barley in the presence of $\mathrm{K}^{*}$ and showed that the intake of ions is not a uni-directional process, but that

\footnotetext{
$\uparrow$ The radioactive form of an element is denoted by an asterisk.
} 
ions of the same species may move into the root and out of the root at the same time. Stout and Hoagland of the same department, using the radioactive isotopes of potassium, sodium, phosphorus, and bromine, studied their upward movement after absorption by the roots in actively growing willow and geranium plants. They found that when salts are absorbed by roots, some portion enters the xylem within very short periods of time, and is carried rapidly towards the leaves under the influence of trans- using low activities in 'tracer' work. Hamilton is making an extensive study of the physiology of the isotopes of sodium, potassium, iodine and other elements, in health and disease. Their rapid absorption and distribution is evidenced by their appearance in the hand a few minutes after oral administration of small amounts. The isotope of iodine is proving to be valuable in the study of thyroid physiology. Hamilton has demonstrated the marked concentration of ingested iodine in the thyroid gland and has been

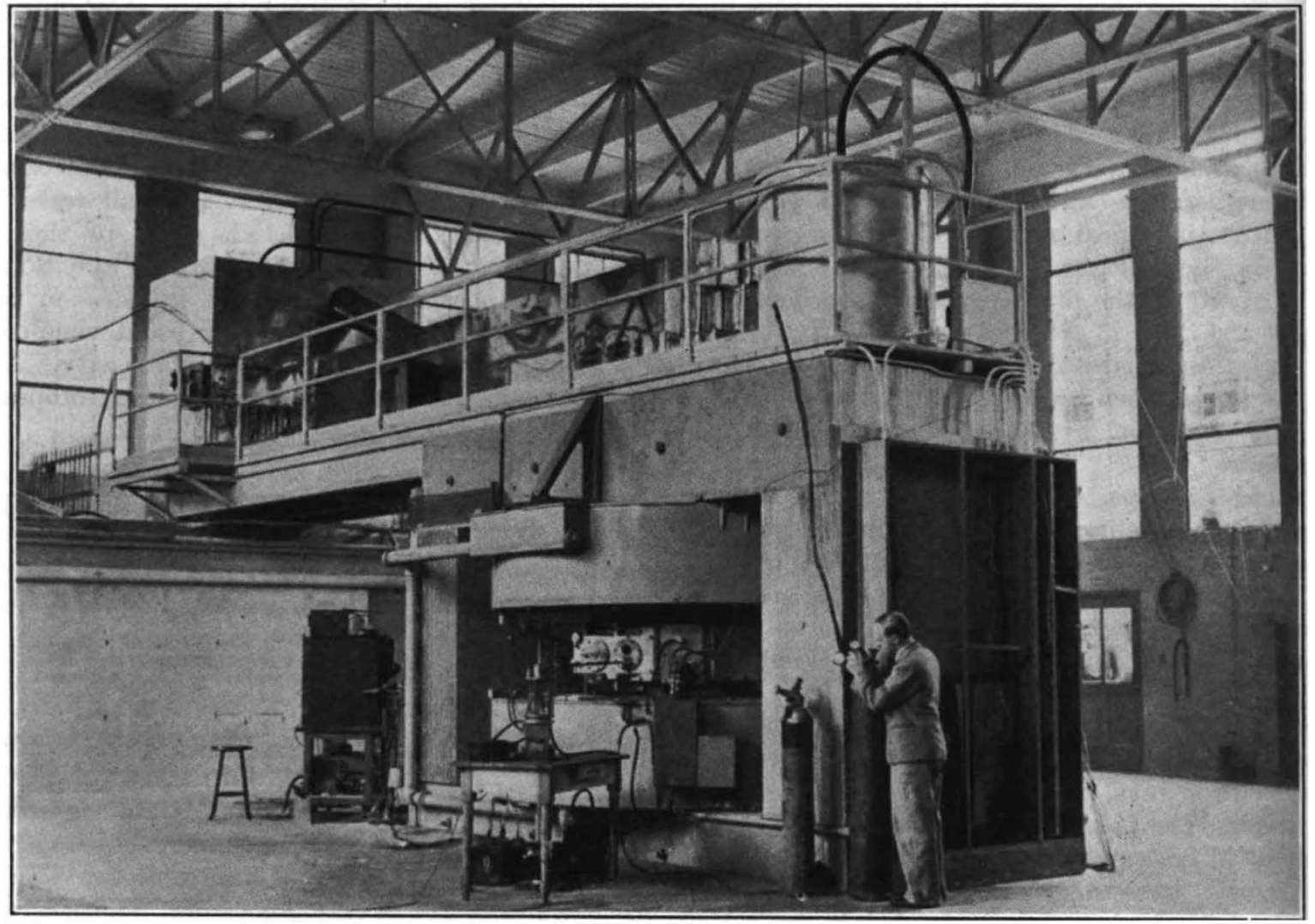

Fig. 1.

The 200-TON 60-Inch cyclotron in the Crocker Radation Laboratory on the Berkeley Campus of the University of California.

Standing by the corner of the magnet and adjusting the helium flow to the target chamber is the late Dr. Harold Walke, of the University of Liverpool. On the table in the foreground is an experimental deuterium generator. The target chamber is behind, marked by the two port holes. Above and to the rear is seen the aluminium oscillator house or radio-frequency power supply. Photograph taken by Dr. Donald Cooksey, assistant director of the Radiation Laboratory.

piration. That the content of radioactivity in the bark as compared with the root is slight indicates that movement of salts in the former is very slow.

Mullins, of the Department of Zoology, has investigated the effect of increasing activities of radio-sodium on the penetration of $\mathrm{Na}^{+}$into the single-celled alga Nitella. His results show that, below certain activity concentrations, there is no 'radiation' effect, and point out the importance of able to photograph the distribution of iodine by placing the excised gland on a photographic film. Anderson and her associates of the Institute of Experimental Biology have found that in adrenalectomized rats a single dose of 'tagged' sodium is rapidly lost, while potassium tends to be retained.

Radio-phosphorus $\left(\mathrm{P}^{32}\right)$ has been the most extensively used radioactive isotope. The ease of manufacture in the cyclotron and its relatively 
long half-life (14:3 days) make it ideal for biological studies. Chaikoff and his associates in their studies of phospholipid metabolism have shown that various kinds of neoplasms in animals have individual rates of phospholipid turnover, and that cell type does not seem to be the determining factor. In association with Scott and Tuttle, the metabolism of labelled phosphorus in leukæmia in both animals and man is being investigated. The finding that in leukæmic mice the phosphorus turnover is apparently proportional to the degree of leukæmic infiltration suggested the use of radiophosphorus as a source of radiation in the treatment of leukæmia in humans. The concentration of the radio-phosphorus in the areas infiltrated with leukæmic cells tends to localize the therapeutic irradiation (beta-rays). Given by mouth in the form of sodium phosphate, phosphorus is well absorbed (75 per cent) and slowly excreted ( 2 per cent per day). The turnover of phosphorus in red cells is rapid, whereas the white cells retain it for longer periods of time. Numerous patients suffering from chronic leukæmia are being treated with this material, and in many instances remissions in the disease are obtained.

Tarver and Schmidt, of the Department of Biochemistry, have synthesized methionine from radio-sulphur and, after feeding it to rats, have shown that the radio-sulphur may later appear as cystine extracted from the tissues. Finally, Whipple and his associates at the University of Rochester, in their studies on normal and anæmic dogs, report the following: radio-iron is poorly absorbed by normal animals ; anæmic animals absorb iron in proportion to their need for it; plasma is the medium for the transport of iron; the rapid appearance of iron in the red blood cells is spectacular.

The intense beam of neutrons produced by the cyclotron has made it possible to investigate their biological effects on various objects such as bacteria, plants, Drosophila eggs, animal tumours and normal mammals. This new penetrating form of radiation has intense biological effects, even greater than $\mathrm{X}$-rays or gamma rays, on normal and tumour tissue, but when compared with X-rays, selectively affects some tissues more than others. Experiments on animals indicating that neutrons are more destructive to neoplastic tissue than to normal tissue suggested their trial in cancer therapy. In association with R. S. Stone, of the Department of Roentgenology, patients suffering from cancer are now regularly being treated with neutrons from the new 60-inch medical eyclotron. The recent experiments of Kruger in this Laboratory have opened up another possible application of neutrons to cancer therapy. $\mathrm{He}$ has demonstrated that cancers from mice placed in non-toxic concentrations of boric acid and irradiated with slow neutrons can be killed with doses of irradiation harmless to tissues not in contact with boron. The slow neutron is captured by the boron nucleus. The combination emits two heavy ionizing particles in

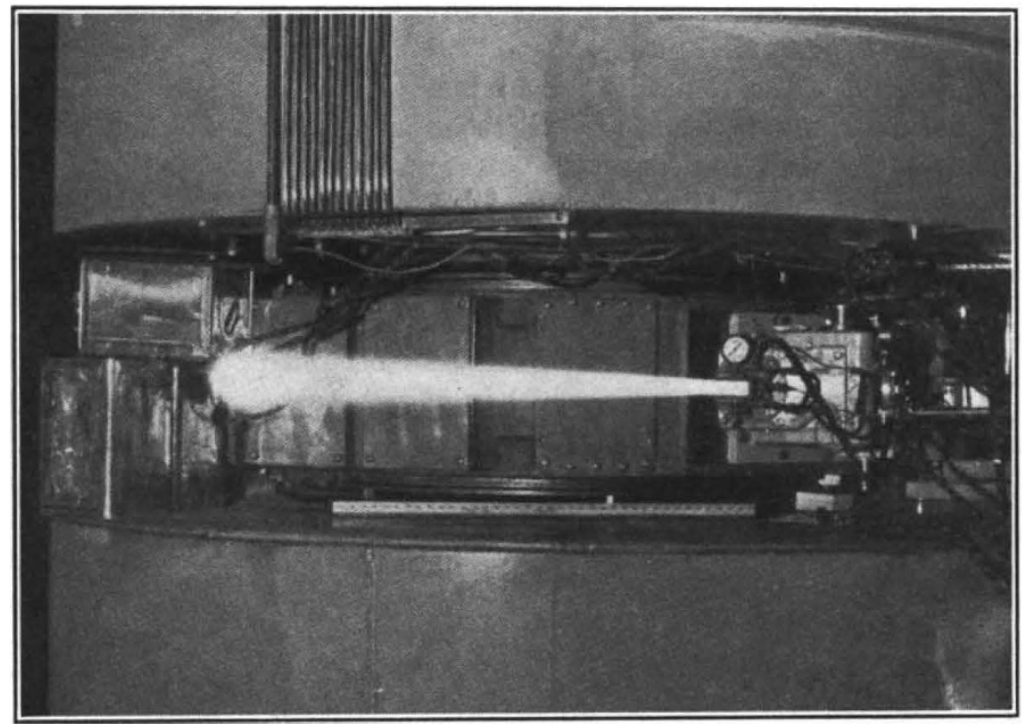

Fig. 2.

The PATH OF A 16-MILLION ELECTRON VOLT DEUTERON BEAM TRAVERSING THE AIR FOR A DISTANCE OF NEARLY FIVE FEET.

These particles emerge from the vacuum of the target chamber with a velocity of approximately 18,000 miles per second. In slowing down over the course of their path, they give up their energy to the air molecules, causing them to glow with a violet light. However, in practice, a target to be made radioactive is placed at the emergent point of the beam and thus bombarded. Where neutrons are desired the target used is beryllium. Photograph taken by Dr. Donald Cooksey, assistant director of the Radiation Laboratory.

opposite directions-an alpha particle and a lithium nucleus-which traverse a distance of about $7 \mu$ in tissue and thus approximate an explosion within the cell.

Although the great contribution of the new nuclear physics to the problems of biology and medicine is certainly the 'labelled' or 'tagged' isotope, nevertheless it seems important to pursue the possibilities of artificial radioactivity and neutron rays in cancer therapy until a more satisfactory answer to this problem has been reached. 